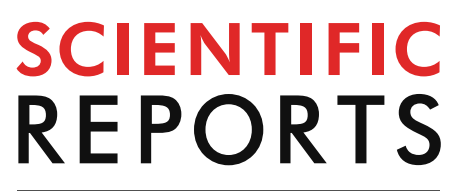

natureresearch

Check for updates

\title{
The Sporomusa type Nfn is a novel type of electron-bifurcating transhydrogenase that links the redox pools in acetogenic bacteria
}

\begin{abstract}
Florian Kremp, Jennifer Roth \& Volker Müller ${ }^{\circledR}$
Flavin-based electron bifurcation is a long hidden mechanism of energetic coupling present mainly in anaerobic bacteria and archaea that suffer from energy limitations in their environment. Electron bifurcation saves precious cellular ATP and enables lithotrophic life of acetate-forming (acetogenic) bacteria that grow on $\mathrm{H}_{2}+\mathrm{CO}_{2}$ by the only pathway that combines $\mathrm{CO}_{2}$ fixation with ATP synthesis, the Wood-Ljungdahl pathway. The energy barrier for the endergonic reduction of NADP+, an electron carrier in the Wood-Ljungdahl pathway, with NADH as reductant is overcome by an electronbifurcating, ferredoxin-dependent transhydrogenase ( $\mathrm{Nfn}$ ) but many acetogens lack $n f n$ genes. We have purified a ferredoxin-dependent NADH:NADP ${ }^{+}$oxidoreductase from Sporomusa ovata, characterized the enzyme biochemically and identified the encoding genes. These studies led to the identification of a novel, Sporomusa type Nfn (Stn), built from existing modules of enzymes such as the soluble $[\mathrm{Fe}-\mathrm{Fe}]$ hydrogenase, that is widespread in acetogens and other anaerobic bacteria.
\end{abstract}

The Wood-Ljungdahl pathway (WLP) is an ancient pathway that combines carbon dioxide fixation with the synthesis of ATP and, therefore, is considered as one of the oldest life sustaining pathways on Earth ${ }^{1,2} \cdot \mathrm{CO}_{2}$ is reduced in two branches (the carbonyl- and the methyl-branch) to CO and a corrinoid-bound methyl group, respectively, by several consecutive enzymatic steps. Subsequently, $\mathrm{CO}$ and the methyl group are condensed and further converted to acetate via acetyl phosphate ${ }^{3,4}$. Acetogenic bacteria are phylogenetically very diverse but the basic chemistry of the WLP is identical. In every acetogen studied so far, ATP is synthesized by substrate level phosphorylation in the acetate kinase reaction, but additional ATP synthesis by a chemiosmotic mechanism is absolutely required for a net ATP synthesis ${ }^{5,6}$. Acetogens differ in the respiratory enzymes used: some use a ferredoxin: $\mathrm{NAD}^{+}$oxidoreductase $(\mathrm{Rnf})^{7-9}$, other a ferredoxin: $\mathrm{H}^{+}$oxidoreductase $(\mathrm{Ech})$ as respiratory enzyme ${ }^{10}$. The ion translocated by these enzymes can be either a proton or a sodium ion ${ }^{11-13}$.

During lithotrophic growth electrons for $\mathrm{CO}_{2}$ reduction are ultimately derived from molecular hydrogen. Therefore, acetogens employ hydrogenases and, again, there is great variety of hydrogenases used: soluble, electron-bifurcating $[\mathrm{Fe}-\mathrm{Fe}]$ hydrogenase ${ }^{14}$ and membrane-bound $[\mathrm{Ni}-\mathrm{Fe}]$ hydrogenases ${ }^{10}$. Along with the diversity of hydrogenases goes the diversity of electron carriers involved in hydrogen oxidation which can be $\mathrm{NAD}^{+}, \mathrm{NADP}^{+}$and/or ferredoxin ${ }^{15-18}$. The same is true for the reduction steps in the WLP: in some organisms, ferredoxin $(\mathrm{Fd})$ and $\mathrm{NAD}^{+}$are the major electron carriers, in others $\mathrm{NADP}^{+}$is also involved ${ }^{5}$. Since electron carriers coupled to oxidation reactions may be different from electron carriers involved in the reductive branch, a redox balancing module is essential to produce the correct electron carriers in the right amount for the WLP . Reduction of ferredoxin is highly endergonic with electrons coming from hydrogen and the energy barrier is overcome either by a soluble energy-coupled, electron-bifurcating hydrogenase that uses $\mathrm{NAD}^{+}$as cooxidant ${ }^{18}$ or by a membrane-bound enzyme, the Rnf complex, that uses reverse electron transfer to drive endergonic ferredoxin reduction with $\mathrm{NADH}$ as reductant ${ }^{9}$. $\mathrm{NADP}^{+}$reduction with $\mathrm{NADH}$ is also endergonic but acetogens 
studied so far lack a membrane-bound transhydrogenase; they use electron bifurcation to overcome the energetic barrier by an NADH-dependent reduced ferredoxin:NADP ${ }^{+}$oxidoreductase (known as Nfn in acetogens) ${ }^{19}$.

Interestingly, some acetogens lack $n f n$ genes and must have a different enzyme to reduce $\mathrm{NADP}^{+}$. To find this missing link, we have studied the metabolism of the acetogen Sporomusa ovata and will provide evidence for a novel type of $\mathrm{NADH}$-dependent reduced ferredoxin:NADP ${ }^{+}$oxidoreductase built from existing redox modules.

\section{Results}

Insights into the central metabolism of S. ovata. The genome of S. ovata was sequenced in 2013 by Poehlein et al. ${ }^{20}$ (accession no.: ASXP00000000). Almost all proteins of the methyl- and the carbonyl branch were found to be encoded in one gene cluster (SOV_1c07560-SOV_1c07730, Supplementary Fig. 1), but the genes encoding a SeCys-containing formate dehydrogenase (Fdh), phosphotransacetylase (Pta) and acetate kinase (Ack) are located somewhere else in the genome (SOV_1c07830+SOV_1c07840, SOV_1c07460 and SOV_1c10930). A search for redox balancing modules revealed genes encoding an electron-bifurcating [FeFe] hydrogenase (SOV_1c07930-SOV_1c07970) and an Rnf complex (SOV_1c08080-SOV_1c08130) but genes encoding an Nfn-type transhydrogenase were not found. Therefore, the basic metabolism of S. ovata is similar to that of Rnf complex-containing acetogens like the model acetogen $A$. woodii ${ }^{5}$. To get a more precise model of the metabolism, the redox carriers involved in the WLP were determined experimentally. To this end, S. ovata was grown and harvested in late exponential growth phase and cells were disrupted by a French pressure cell. After cell debris was removed, membranes were separated from the cytoplasmic fraction by ultracentrifugation and enzyme activities were measured as described in methods. The membrane fraction catalysed ferredoxindependent $\mathrm{NAD}^{+}$reduction $\left(0.14 \mathrm{U} / \mathrm{mg}\right.$ ), $\mathrm{NADP}^{+}$was not reduced (Supplementary Fig. 2a, 2b and 2c). Unlike A. woodii but like $M$. thermoacetica, the methylene-THF dehydrogenase (MTHFDH), which was measured in the cytoplasmic fraction, did not reduce $\mathrm{NAD}^{+}$but $\mathrm{NADP}^{+}(33 \mathrm{U} / \mathrm{mg}$ ) (Supplementary Fig. 3a and 3b). These findings show that $S$. ovata uses both, NADH and NADPH as reductants in the WLP but since there is neither an Nfn complex nor a membrane-bound transhydrogenase encoded in the genome of S. ovata, the question arose of how the NADH- and Fd-pools are coupled to the NADPH-pool. Transhydrogenases are described to have a high diaphorase activity and, therefore, we decided to search for and enrich an NADPH:methyl viologen (MV) oxidoreductase activity from the cytoplasmic fraction.

Purification and analysis of an NADPH:MV oxidoreductase. The cytoplasmic fraction of S. ovata catalysed NADPH:MV oxidoreductase with an activity of $3 \mathrm{U} / \mathrm{mg}$. The activity was enriched 93 -fold by fast liquid chromatography (FPLC) on Q-Sepharose, Phenyl-Sepharose, Superdex 200 and Blue-Sepharose from 3 to $278 \mathrm{U} / \mathrm{mg}$ (Supplementary Table 1). Three major proteins with molecular masses of 128, 65 and $16 \mathrm{kDa}$ became visible after separation of the preparation by SDS-PAGE (Fig. 1). To analyse whether these proteins are part of a single protein complex, the enriched sample was separated by native PAGE which revealed three protein complexes with molecular masses of approximately 232, 142 and $91 \mathrm{kDa}$ (Supplementary Fig. 4a). The protein complexes were cut out of the gel, treated with $2 \%$ SDS and $0.67 \%$ mercaptoethanol in $60 \mathrm{mM} \mathrm{Na}_{2} \mathrm{CO}_{3}$ and separated in a denaturating SDS-PAGE (Supplementary Fig. 4b). The protein complex with a molecular mass of 232 was separated into the three proteins seen before $(128,65$ and $16 \mathrm{kDa})$, showing that they are part of a single complex. The protein complex with a molecular mass of $142 \mathrm{kDa}$ contained two major proteins of 128 and $65 \mathrm{kDa}$, indicating decomposition of the complex during native PAGE. The third protein complex with a size of $91 \mathrm{kDa}$ contained two proteins with apparent molecular masses of 65 and $72 \mathrm{kDa}$, indicating a minor contamination in the preparation. This is corroborated by the observation that a $72 \mathrm{kDa}$ protein is not consistently observed in the preparations. Since the complex was shown to decompose during gel electrophoresis the molecular mass was determined by analytical gel filtration on Superdex 200; it amounted to approximately $840 \mathrm{kDa}$, consistent with the mass of a tetrameric heterotrimer. The proteins with a molecular mass of 128, 65 and $16 \mathrm{kDa}$ were identified by MALDI-TOF-MS analysis to be encoded by the three consecutive genes SOV_1c07740-SOV_1c07760 which are located downstream of the WLP encoding gene cluster (Fig. 1).SOV_1c07740-SOV_1c07760 are annotated as NuoE-, NuoF- and GltD/NuoG-like proteins.

Activities and basic properties of the reactions catalysed by the purified enzyme. The purified protein complex exhibited not only NADPH:methyl viologen but also NADPH:benzyl viologen (BV) activity $(238.0 \mathrm{U} / \mathrm{mg})$. Besides, NADH can be used as electron donor for MV and BV reduction $(0.33 \mathrm{U} / \mathrm{mg}$ and $0.23 \mathrm{U} /$ $\mathrm{mg}$ ), indicating a possible function as transhydrogenase which connects the NADPH with the NADH-pool. Indeed $\mathrm{NAD}^{+}$could be reduced with electrons from $\mathrm{NADPH}$, albeit with low activity $(0.06 \mathrm{U} / \mathrm{mg})$. Furthermore, FAD (3.2 U/mg) and FMN $(5.2 \mathrm{U} / \mathrm{mg})$ were reduced with NADPH as reductant, demonstrating that flavin molecules can bind to the Stn complex, which is a key feature of electron-bifurcating enzymes. The complex reduced ferricyanide $(315 \mathrm{U} / \mathrm{mg}$ ) with NADPH, indicating that the Stn complex also uses iron containing electron donors/acceptors, besides pyridine nucleotides. Next, we tested if Fd (reduced by CODH), which is used by electron-bifurcating enzymes as low potential electron acceptor, can serve as electron donor for the energetic "downhill" electron transport to $\mathrm{NADP}^{+}$or $\mathrm{NAD}^{+}$and, indeed, $\mathrm{NADP}^{+}-$and $\mathrm{NAD}^{+}$reduction was observed with 0.65 and $0.23 \mathrm{U} / \mathrm{mg}$, respectively. Since Fd, NADP $(\mathrm{H})$ and $\mathrm{NAD}(\mathrm{H})$ are used as electron donors/ acceptors, we tested if the Stn complex uses the mechanism of flavin-based electron bifurcation (FBEB). Therefore, simultaneous reduction of $\mathrm{NAD}^{+}$and $\mathrm{Fd}$ with $\mathrm{NADPH}$ was tested and, indeed, reduction of $\mathrm{NAD}^{+}$was found with a maximum activity of $4.5 \mathrm{U} / \mathrm{mg}$ and $\mathrm{Fd}$ was reduced with a maximal activity of $3.0 \mathrm{U} / \mathrm{mg}$ under optimal conditions of $50^{\circ} \mathrm{C}$ and $\mathrm{pH} 8$ (Supplementary Fig. $5 \mathrm{a}$ and $5 \mathrm{~b}$ ). Reduction of $\mathrm{NAD}^{+}$did not stop after ferredoxin was fully reduced, as it was observed for the electron-bifurcating hydrogenase of Desulfovibrio fructosovorans, indicating reoxidation of $\mathrm{Fd}_{\mathrm{red}}{ }^{21}$. $\mathrm{K}_{\mathrm{m}}$-values were determined to be $39 \mu \mathrm{M}$ for NADPH and $59 \mu \mathrm{M}$ for 


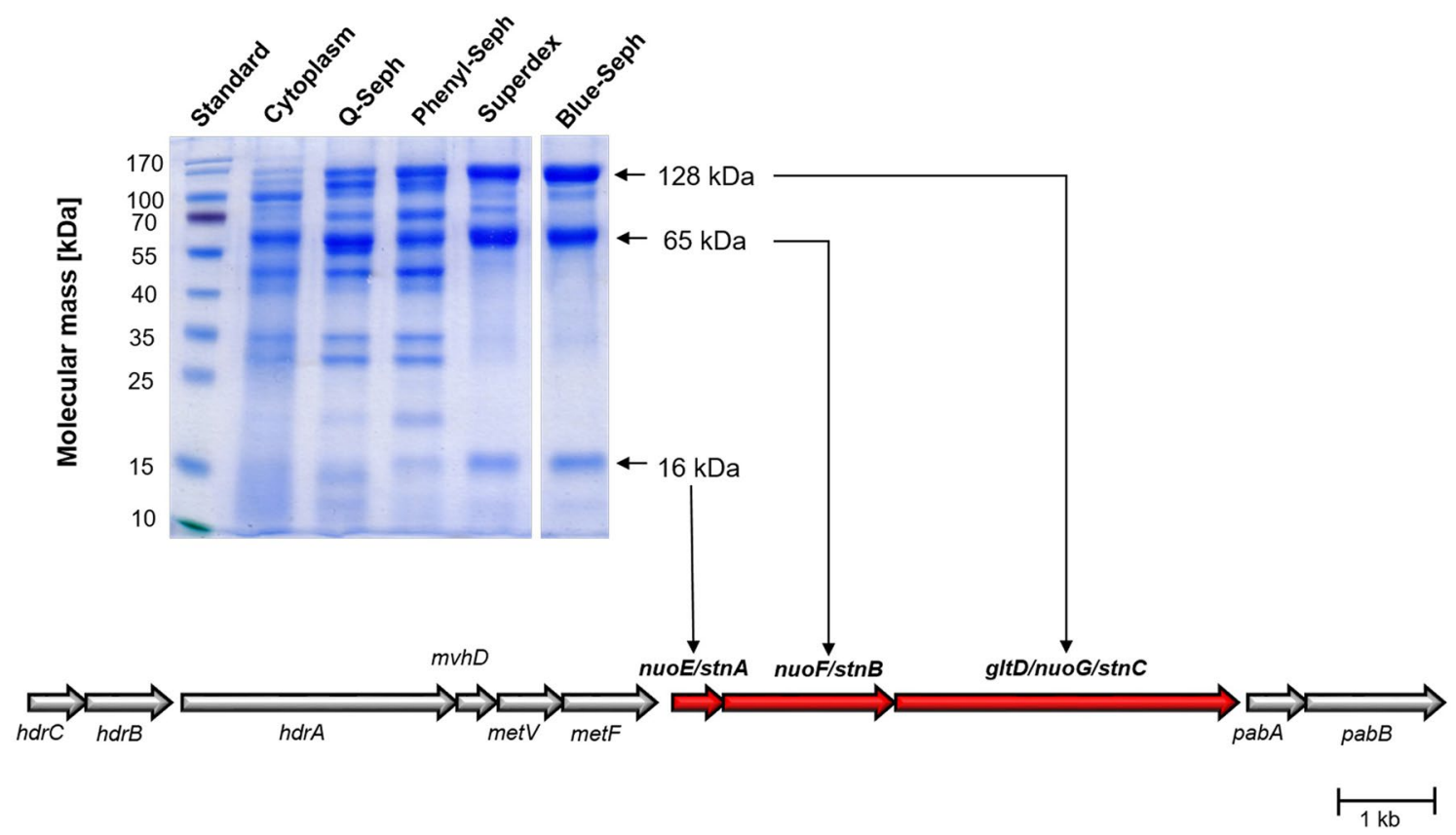

Figure 1. Purification of the Sporomusa type Nfn complex of S. ovata. $10 \mu \mathrm{g}$ of protein sample from each purification step were separated in a denaturating SDS-PAGE. MALDI-TOF-MS analysis of the proteins with the apparent molecular masses of 128,65 and $16 \mathrm{kDa}$ identified the encoding genes to be located downstream of the MTHFR encoding genes (met $V F$ ) and upstream of $p a b A B$ which encode an aminodeoxychorismate/ anthranilate synthase. The Stn encoding genes were annotated to code for Nuo-like proteins ( $n u o E$, nuoF and $n u o G)$. Further, $\operatorname{stn} C$ was annotated to code for a protein which is in part similar to GltD, the small subunit of glutamate synthases.

$\mathrm{NAD}^{+}$(Supplementary Fig. 6a and 6b). Further, the enzyme catalysed $\mathrm{Fd}_{\text {red }}$-and NADH-dependent reduction of $\mathrm{NADP}^{+}$with a maximal activity of $5.0 \mathrm{U} / \mathrm{mg}$ and half maximal activity was found with concentration of $31 \mu \mathrm{M}$ $\mathrm{NADP}^{+}$or $40 \mu \mathrm{M}$ NADH (Supplementary Fig. $6 \mathrm{c}$ and $6 \mathrm{~d}$ ). Addition of FMN $(50 \mu \mathrm{M})$ to the bifurcation assay stimulated the $\mathrm{NAD}^{+}$- and Fd reduction $\sim 3-4$-fold to $17 \mathrm{U} / \mathrm{mg}$ and $10 \mathrm{U} / \mathrm{mg}$, respectively. $\mathrm{NADP}^{+}$reduction with $\mathrm{Fd}_{\text {red }}$ and $\mathrm{NADH}$ was stimulated $\sim$ eightfold to $42 \mathrm{U} / \mathrm{mg}$. Also FAD $(50 \mu \mathrm{M})$ stimulated the activities but to a smaller extent.

The experiments described above are consistent with the hypothesis that the complex catalyses NADHdependent $\mathrm{NADP}^{+}$reduction with simultaneous oxidation of reduced ferredoxin as energetic driving force by flavin-based electron confurcation. To determine the stoichiometries of the reactants involved, the reverse reaction was analysed. In order to run the reaction for a longer period the standard assay was altered: The level of NADPH was kept constant with an NADPH regeneration system $\left(0.4 \mathrm{mM} \mathrm{NADP}{ }^{+}, 40 \mathrm{mM}\right.$ glucose-6-phosphate and $1 \mathrm{U}$ glucose-6-phosphate dehydrogenase) and $180 \mu \mathrm{M} \mathrm{Fd}$ and $1 \mathrm{mM} \mathrm{NAD}{ }^{+}$were used in the assay. The stoichiometry of $\mathrm{NAD}^{+}$reduced per ferredoxin reduced was calculated to be 1.3 from the concentrations of NADH and $\mathrm{Fd}_{\text {red }}$ measured in 5-s intervals (Fig. 2a, b). Under completely coupled conditions $\mathrm{NAD}^{+}$and $\mathrm{Fd}$ are expected to be reduced in a 1:1 stoichiometry according to Eq. 1:

$$
2 \mathrm{NADPH}+\mathrm{NAD}^{+}+\mathrm{Fd}_{\mathrm{ox}} \rightarrow 2 \mathrm{NADP}^{+}+\mathrm{NADH}+\mathrm{Fd}_{\text {red }}
$$

but since the complex also catalyses $\mathrm{NAD}^{+}$reduction with only $\mathrm{NADPH}$ or $\mathrm{Fd}_{\text {red }}$ as electron donor and reoxidation of $\mathrm{Fd}_{\text {red }}$ occurs, the deviation can be explained. Ratios of NADPH oxidised to Fd reduced were calculated to be 1.4 by using the same assay without NADPH regeneration system, but $0.5 \mathrm{mM}$ NADPH instead and only $120 \mu \mathrm{M}$ Fd (Fig. 3a, b). NADH and NADPH both absorb at $340 \mathrm{~nm}$ and have the same extinction coefficient, therefore the expected ratio of NADPH oxidised per Fd reduced of 2 (Eq. 1) was adjusted, by the theoretical amount of $\mathrm{NAD}^{+}$reduced, to 1 . Again, deviation from the theoretical value is expected, since the complex also couples the individual reactions.

In sum, the purified NADH:MV oxidoreductase from $S$. ovata is a novel type of Nfn complex that catalyses $\mathrm{NADH}$-dependent $\mathrm{Fd}_{\text {red }}: \mathrm{NADP}^{+}$oxidoreductase activity. Therefore, we propose the name Sporomusa type Nfn (Stn) for the heterotrimeric protein complex, comprising of the $16 \mathrm{kDa}$ subunit $\mathrm{Stn} \mathrm{A}$, the $65 \mathrm{kDa}$ subunit $\operatorname{StnB}$ and the $128 \mathrm{kDa}$ subunit StnC. Because StnC was also annotated as formate dehydrogenase, formate oxidation with methyl viologen as electron acceptor was tested, but no activity was observed.

In silico analysis of the genes coding for Stn and basic biochemical properties. Sequence comparison using BlastP algorithm revealed 57.5, 49.6, 38.6, 37.3 and 34.7\% identity of StnA to subunit NsoA of the NADPH-dependent sulfur/oxygen oxidoreductase from Thermococcus litoralis ${ }^{22}$, HydC of the electronbifurcating hydrogenase from $A$. woodii ${ }^{18}$ and the $\mathrm{NAD}(\mathrm{H})$-dependent hydrogenase of Syntrophomonas wolfe $i^{23}$, 
a

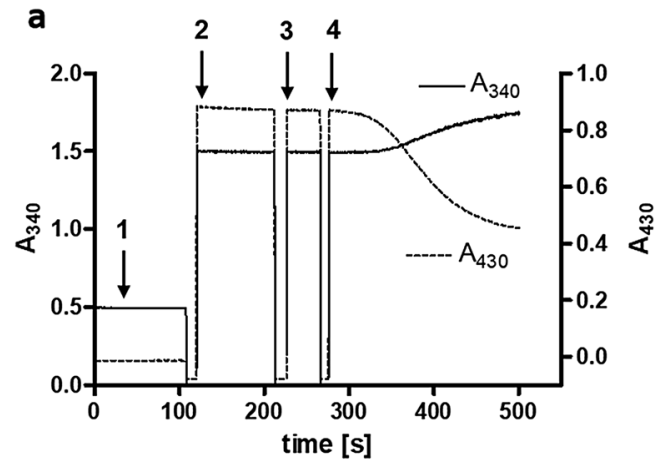

b

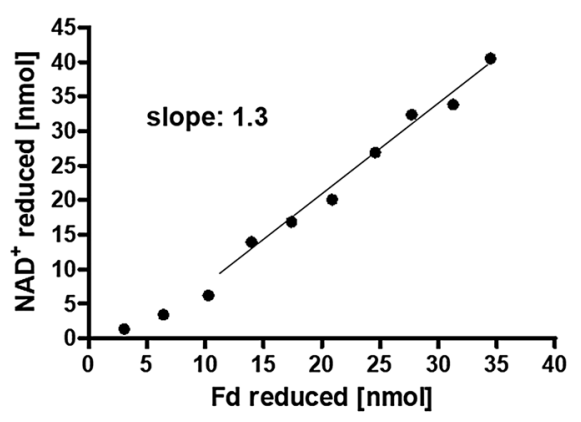

Figure 2. Stoichiometry of $\mathrm{NAD}^{+}$and Fd reduced. (a) $0.4 \mathrm{mM} \mathrm{NADP}^{+}$was reduced with glucose-6-phosphate dehydrogenase and $40 \mathrm{mM}$ glucose-6-phosphate to ensure a constant level of NADPH during the assay (1). $180 \mu \mathrm{M} \mathrm{Fd}$ and $1 \mathrm{mM} \mathrm{NAD}{ }^{+}$were added (2 and 3 ) and the assay was started by addition of $6.5 \mu \mathrm{g}$ protein (4). The reduction of $\mathrm{NAD}^{+}$and ferredoxin were followed at $340 \mathrm{~nm}$ and $430 \mathrm{~nm}$, respectively. The amount of $\mathrm{NAD}^{+}$ and ferredoxin reduced was calculated from (a) in 5-s intervals and applied in (b) to calculate the ratio of $\mathrm{NAD}^{+}$ reduced to ferredoxin reduced.

a

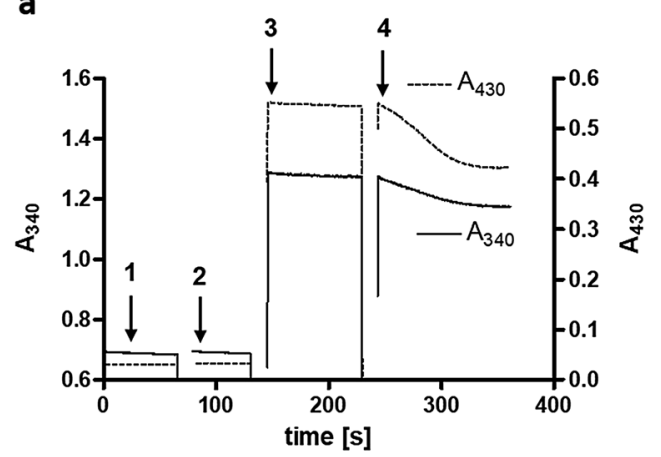

b

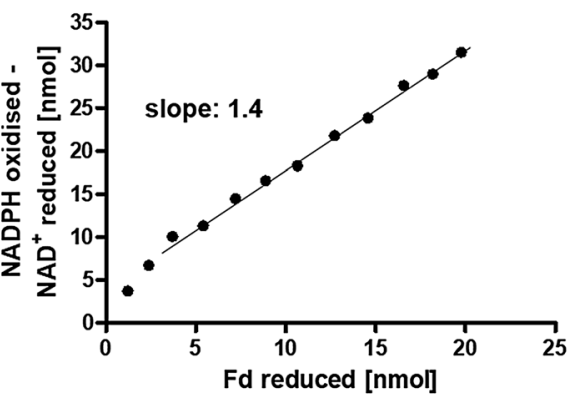

Figure 3. Stoichiometry of NADPH oxidised per Fd reduced. (a) $0.5 \mathrm{mM} \mathrm{NADPH}$ (1), $1 \mathrm{mM} \mathrm{NAD}^{+}(2)$ and $120 \mu \mathrm{M} \mathrm{Fd}$ (3) were added to the buffer and the assay was started with $9.75 \mu \mathrm{g}$ protein (4). The oxidation of NADPH and the reduction of ferredoxin were followed at $340 \mathrm{~nm}$ and $430 \mathrm{~nm}$, respectively. The amount of NADPH oxidised and ferredoxin reduced were calculated from (a) in 5-s intervals and applied in (b) to calculate the ratio of NADPH oxidised minus $\mathrm{NAD}^{+}$reduced to ferredoxin reduced.

NuoE of complex I from E. coli ${ }^{24}$ and HndA of the electron-bifurcating hydrogenase from D. fructosovorans $s^{21,25}$, respectively (Fig. 4). StnA is predicted to have a molecular mass of $19 \mathrm{kDa}$ and a thioredoxin-like domain with conserved [2Fe-2S]-binding motif (Supplementary Fig. 7). StnB is a homolog of the subunits NsoB, HndC, HydB and NuoF from the same protein complexes, sharing 64.5, 61.4, 59.9, 50.4 and $44.3 \%$ identity, respectively. StnB has a predicted molecular mass of $63.5 \mathrm{kDa}$ and the GxGxxG motif indicative for NADH-binding ${ }^{26,27}$ as well as the FMN-binding region ${ }^{28}$ are conserved. Additionally, the [4Fe-4S]-cluster binding residues of NuoF are conserved in StnB (Supplementary Fig. 8). As in StnA the N-terminus is proposed to form a thioredoxin-like domain, but unlike in StnA 2 of the 4 cysteines responsible for [2Fe-2S]-cluster binding are changed to glycine. The C-terminus of StnB has two more predicted [4Fe-4S]-binding sites that are also found in HydB and NsoB. StnC seems to be a fusion of an N-terminal GltD-like domain and a C-terminal NuoG-like domain. NsoC also combines these two domains and shows $40.6 \%$ identity to StnC. Further the N-terminal domain of StnC shows identities of 40.2, 39.9, 39.2 and $37.2 \%$ to subunit SudA from a sulfide dehydrogenase/ferredoxin:NADPH oxidoreductase of Pyrococcus furiosus ${ }^{29-31}$, subunit SfrB of the NADPH:Fe ${ }^{3+}$ oxidoreductase from Geobacter sulfurreducens $^{32}$, the NADPH-binding subunit NfnB from the Nfn complex of C. kluyveri ${ }^{19}$ and subunit GltD of the glutamate synthase of $E$. coli, respectively. The C-terminal domain of StnC is slightly similar to subunit SfrA from G. sulfurreducens and NuoG from E. coli showing identities of 27.8 and $25.6 \%$. StnC is predicted to have a molecular mass of $126.4 \mathrm{kDa}$ and a proposed $\mathrm{N}$-terminal [2Fe-2S]-ferredoxin domain, but only 5 of $8 \mathrm{FeS}$ coordinating residues from SudA, SfrB and GltD are conserved in StnC (Supplementary Fig. 9). Two glycinerich regions are found in StnC. The first is proposed to be part of an FAD-binding motif ${ }^{27}$, whereas the second motif GxGxxA is proposed to bind $\mathrm{NADP}(\mathrm{H})$ rather than $\mathrm{NAD}(\mathrm{H})^{33}$. The C-terminal domain has a proposed [4Fe-4S]-dicluster domain and a [4Fe-4S]-cluster of the molybdopterin oxidoreductase family (Supplementary

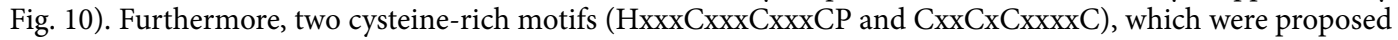
to be a product of the integration of GltD into a NuoG-like protein ${ }^{22}$, are conserved in StnC but whether they 
GItD 37.2

E. coli

FAD NADPH FADII

SudA / NfnB $\quad 40.2 / 39.2$

P. furiosus / C. kluyveri

FAD NADPH FADII

SfrB 39.9

G. sulfurreducens

FAD NADPH FADI

SfrA 27.8

G. sulfurreducens

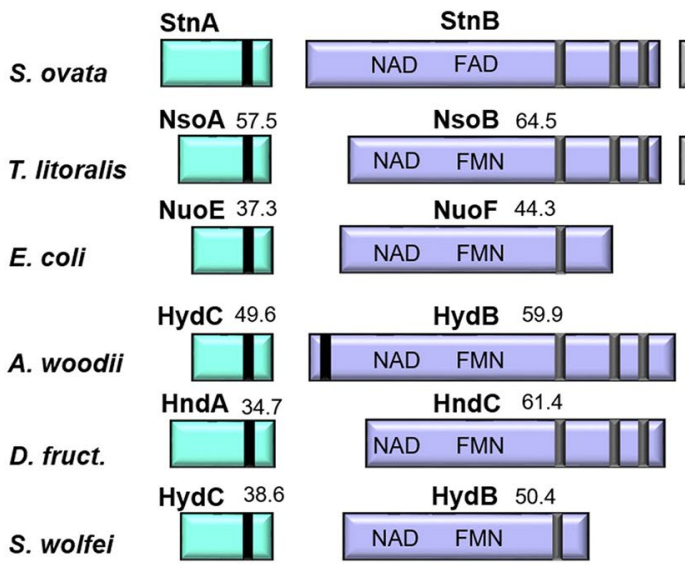

Figure 4. Comparison of Stn subunits to homologous proteins. StnA is a homolog of NuoE-like proteins and StnB belongs to the NuoF-like protein family both known to be part of electron-bifurcating enzymes such as the bifurcating hydrogenases of several organisms (e.g. A. woodii). StnC seems to be a fusion of a GltD-like and a NuoG-like protein. The family of GltD-like proteins has also members, participating in electron bifurcation (e.g. $\mathrm{NfnB}$ of C. kluyveri). The depicted proteins are glutamate synthase small subunit GltD of $E$. coli, the homologous subunits SudA and NfnB from sulfide dehydrogenase and NADH-dependent reduced ferredoxin:NADP ${ }^{+}$ oxidoreductase of $P$. furiosus and C. kluyver $^{19,29,30}$, the subunits SfrB and SfrA from the soluble Fe(III) reductase of G. sulfurreducens ${ }^{32}$, the subunits NsoA, NsoB and NsoC of the NADPH-dependent sulfur oxidoreductase from T. litoralis ${ }^{22}$, NuoE, NuoF and NuoG from the NADH-binding module of complex I from $E$. coli ${ }^{24}$, the subunits HydC and HydB (HndA and HndC) from the electron-bifurcating hydrogenase of $A$. woodii and $D$. fructosovorans ${ }^{18,21}$, respectively, and the subunits HydC and HydB from the non-bifurcating hydrogenase of $S$. wolfe $^{23}$. Numbers indicate sequence identity on protein level. Black bars represent $[2 \mathrm{Fe}-2 \mathrm{~S}]$-clusters, grey bars represent $[4 \mathrm{Fe}-4 \mathrm{~S}]$-clusters and white bars represent cysteine-rich sequences known from $\mathrm{Nso}^{22}$. FAD, FMN and $\mathrm{NAD}(\mathrm{P})$-binding sites are indicated.

bind FeS-cluster is not known so far. In sum, the Stn complex is predicted to bind $32 \mathrm{~mol}$ of Fe and sulfur and one mol FMN and FAD per heterotrimer. Using the method of Fish ${ }^{34} 35.5 \pm 2$ mol of Fe were determined per mol of protein $(n=8)$, indicating that at least one of the two before mentioned cysteine-rich motifs in StnC might bind an FeS-cluster. Contrary to our expectations, after precipitation of the protein and subsequent separation of the flavin-containing supernatant by thin layer chromatography (TLC), FAD was identified to be the only flavin bound (Supplementary Fig. 11). The exact amount of bound FAD could not be determined since flavins are only loosely bound and need to be added to the buffers during purification to prevent loss of protein activity.

Biochemical properties of heterologously produced StnC. The genes $\operatorname{stn} A, \operatorname{stn} B$ and $\operatorname{stn} C$ encoding the single subunits were cloned between the NheI and BamHI restriction sites of pET21a adding a strep-tag encoding sequence at the N-terminus. The plasmids pET21a_strepStnA, pET21a_strepStnB and pET21a_strepStnC were transformed in E. coli BL21 (DE3) $\Delta i s c R$ and produced according to Demmer et al. ${ }^{35}$. Production of strep-tagged StnA and StnB resulted in the formation of inclusion bodies, hence further biochemical analysis was not possible. Strep-tagged StnC was purified to apparent homogeneity using one step purification on StrepTactin and an additional purification step using FPLC on Superdex 200. The purified protein exhibited NADPH oxidation with methyl viologen, FAD, FMN and ferricyanide with activities of 58, 0.7 and 4.5, $16 \mathrm{U} / \mathrm{mg}$, respectively. The identity of bound Flavin was elucidated by TLC to be FAD.

Model of acetogenesis from $\mathrm{H}_{2}+\mathrm{CO}_{2}$ in S. ovata. The results of this study lead to a genome-based model of the central metabolism of $S$. ovata, which is expanded by biochemical analysis. The formate dehydrogenase shows highest similarity to the Fd-dependent Fdh of C. pasteurianum and therefore Fd is assumed as electron donor for $\mathrm{CO}_{2}$ reduction ${ }^{36}$. The MTHFDH was experimentally demonstrated to be NADPH-dependent. The core subunits of methylene-THF reductase (MTHFR) MetV and MetF are encoded downstream of Hdr- and 
Mvh-like genes (Supplementary Fig. 1). A similar genetic arrangement was shown before in M. thermoacetica and the MTHFR was proposed to be a hexaheteromeric complex of HdrCBA, MvhD and MetVF which uses $\mathrm{NADH}$ to reduce methylene-THF and a second so far unknown electron acceptor energetically similar to $\mathrm{Fd}^{37}$. For simplicity reasons, we assume $\mathrm{Fd}$ as second electron acceptor in our model. As mentioned earlier, $\mathrm{CO}_{2}$ reduction to $\mathrm{CO}$ requires $\mathrm{Fd}_{\text {red }}$. During growth on $\mathrm{H}_{2}+\mathrm{CO}_{2}$, electrons are transferred from four $\mathrm{H}_{2}$ to two $\mathrm{Fd}$ and two $\mathrm{NAD}^{+}$by the electron-bifurcating hydrogenase. One $\mathrm{Fd}_{\text {red }}$ is used for $\mathrm{CO}_{2}$ reduction by the Fdh. 0.5 $\mathrm{NADH}$ and $\mathrm{Fd}_{\text {red }}$ are used by the Stn complex for the reduction of one $\mathrm{NADP}^{+}$, which is required in the methyl branch for the reduction of methenyl-THF. $0.5 \mathrm{Fd}_{\text {red }}$ are used by the Rnf complex for the reduction of $0.5 \mathrm{NADH}$, thereby generating a $\mathrm{H}^{+}$-gradient across the membrane. The resulting $0.5 \mathrm{NADH}$ plus the left over $1.5 \mathrm{NADH}$ from $\mathrm{H}_{2}$ oxidation are used by the MTHFR for the simultaneous reduction of methylene-THF and Fd. The reduced ferredoxin can then be used in the carbonyl branch for $\mathrm{CO}_{2}$ reduction. Next, $\mathrm{CO}$ and the methyl group are condensed to build acetyl-CoA. Further conversion finally yields one acetate from four $\mathrm{H}_{2}$ and two $\mathrm{CO}_{2}$. Since the net yield of ATP by substrate level phosphorylation in the WLP is zero, net ATP gain originates from the respiratory chain consisting of the Rnf complex and ATP synthase. Assuming a $\mathrm{H}^{+} / \mathrm{ATP}$ ratio of 4, 0.25 ATP can be synthesised by the $\mathrm{H}^{+}$-gradient (Fig. 5).

\section{Discussion}

Electron bifurcation is a mechanism to couple endergonic to exergonic redox reactions widely distributed in anaerobic bacteria. It is not involved in energy conservation but since ATP is not used as driving force for the endergonic reaction, it saves cellular $\mathrm{ATP}^{38}$. To date, eleven classes of electron-bifurcating enzymes that use the mechanism of FBEB are known ${ }^{39}$. In general FBEB is based on the feature of flavins to have three redox states ${ }^{40}$. During FBEB the bifurcating flavin is fully reduced by a $2 \mathrm{e}^{-}$donor. In the fully reduced state the redox potential of the flavin/semiquinone couple is sufficient for the transfer of one electron to a high potential electron acceptor, leaving a flavin radical with an extremely negative redox potential. The highly reactive flavin radical is now able to reduce a second electron acceptor with a more negative redox potential than the first acceptor ${ }^{38,41,42}$. The $\mathrm{Nfn}$ complex is the most widely distributed electron-bifurcating enzyme and a well-studied specimen ${ }^{43}$. It has two subunits, NfnA and NfnB. NfnB harbours two [4Fe-4S]-clusters, the bifurcating FAD and the NADP $(\mathrm{H})$ and ferredoxin binding sites. NfnA binds a [2Fe-2S]-cluster and an FMN and has the NAD(H) binding site. In the bifurcation mode, two electrons coming from NADPH are transferred to the bifurcating FAD. One electron travels via the $[2 \mathrm{Fe}-2 \mathrm{~S}]$-cluster to the FMN in $\mathrm{NfnA}$, leaving a low potential $\mathrm{FADH}^{\circ-}$ radical in $\mathrm{NfnB}$, which is required for the reduction of the low potential electron acceptor ferredoxin via the two [4Fe-4S]-clusters of $\mathrm{NfnB}^{31,44}$. After a second cycle, the high potential electron acceptor $\mathrm{NAD}^{+}$is reduced in a two electron transfer step from NfnA bound $\mathrm{FMNH}^{-}$(Fig. 6a).

In contrast to Nfn complexes, little is known about the mechanism of electron bifurcation in electron-bifurcating hydrogenases. The core enzyme consists of three subunits, HydA, HydB and HydC ${ }^{14}$. The small subunit HydC coordinates one [2Fe-2S]-cluster. HydA is proposed to harbour the $\mathrm{H}$-cluster for $\mathrm{H}_{2}$ oxidation, three [4Fe-4S]and one $[2 \mathrm{Fe}-2 \mathrm{~S}]$-cluster. HydB is proposed to coordinate three $[4 \mathrm{Fe}-4 \mathrm{~S}]$ - and one $[2 \mathrm{Fe}-2 \mathrm{~S}]$-cluster as well and to harbour the FMN and the $\mathrm{NAD}(\mathrm{H})$ binding sites (Fig. 6b). Furthermore, comparison of HydB homologs of the electron-bifurcating hydrogenase of $A$. woodii ${ }^{18}$ and the non-bifurcating hydrogenase of $S$. wolfe $i^{23}$, suggested that either the $[2 \mathrm{Fe}-2 \mathrm{~S}]$-cluster or one of the C-terminal [4Fe-4S]-clusters of HydB might be the region of Fd binding (Figs. 4, 6b, c). Meanwhile it was found that the hydrogenase of $D$. fructosovorans (Hnd), which also lacks the $\mathrm{N}$-terminal $[2 \mathrm{Fe}-2 \mathrm{~S}]$-cluster in the HydB homolog $(\mathrm{HndC})$, is an electron-bifurcating enzyme ${ }^{21}$, leaving the C-terminal [4Fe-4S]-clusters of $\mathrm{HydB}$ as candidate for Fd binding (Figs. 4, 6d). In electron-bifurcating hydrogenases electrons are transferred from $\mathrm{H}_{2}$ to the FeS-cluster of the $\mathrm{H}$-cluster in HydA, but the further electron flow is uncertain. One possibility is that electron-bifurcating hydrogenases harbour a second, electron-bifurcating flavin. If so, electrons are transferred from the $\mathrm{H}$-cluster to the bifurcating flavin. Here, electrons are split up and two strings of FeS-clusters guide one electron to FMN in HydB and one electron to Fd, respectively ${ }^{14,45}$. Again, a second cycle is required to reduce $\mathrm{NAD}^{+}$with electrons from $\mathrm{FMNH}^{-}$. Another mechanism suggests that the $\mathrm{H}$-cluster is the site of electron bifurcation. In this model electrons are split up directly to two different FeS-strings, the first one leading to FMN in HydB and the second one to the Fd binding site ${ }^{46}$.

The Stn complex seems to be a hybrid built by homologs of HydC, HydB and a protein which is in part similar to NfnB. StnA and StnB are 49.6 and 59.9\% identical to HydC and HydB of the bifurcating hydrogenase of $A$. woodii. Like HydC, StnA is predicted to bind a [2Fe-2S]-cluster. StnB is proposed to bind three [4Fe-4S]-clusters and a Flavin molecule and, therefore, harbours the $\mathrm{NAD}(\mathrm{H})$ binding site. Due to sequence analysis FMN was expected to be bound by StnB but only FAD was detected in the Stn complex by TLC. This is why we suggest an FAD molecule bound in StnB in our model (Fig. 6e). The third subunit is in part (amino acids 1-500) similar to the NADP(H)-binding subunit $\mathrm{NfnB}$ of $\mathrm{Nfn}$ complexes (e.g. 40.2 and $39.2 \%$ identity to SudA/NfnB of $P$. furiosus and C. kluyveri). StnC is proposed to bind at least four [4Fe-4S]-clusters, one [2Fe-2S]-cluster and one FAD (Supplementary Fig. 9) and recombinant StnC indeed binds FAD and oxidises NADPH. Contrary to $\mathrm{NfnB}$, the $[4 \mathrm{Fe}-4 \mathrm{~S}]$-cluster responsible for Fd reduction is not conserved in StnC. However, the C-terminal NuoG-like part of StnC adds further FeS-clusters to the complex, which might form a site for ferredoxin reduction. This is consistent with the presence of a conserved arginine residue in StnC (Arg239, Arg201 in SudA of P. furiosus; Supplementary Fig. 9), which is thought to have a major role in adjusting the low redox potential of the FADH ${ }^{\circ-} / \mathrm{FAD}$ pair needed for ferredoxin reduction in Nfn complexes ${ }^{43,44}$. Hence, we propose that the electrons from NADPH are transferred to the FAD bound by StnC first. Subsequently, the electrons are split up and shuttled via two distinct FeS-strings to FAD in StnB and the Fd bound by either StnC or StnB (Fig. 6e). The composition of the distinct FeS-strings and which FeS-cluster enables electron transfer from the Stn complex to 


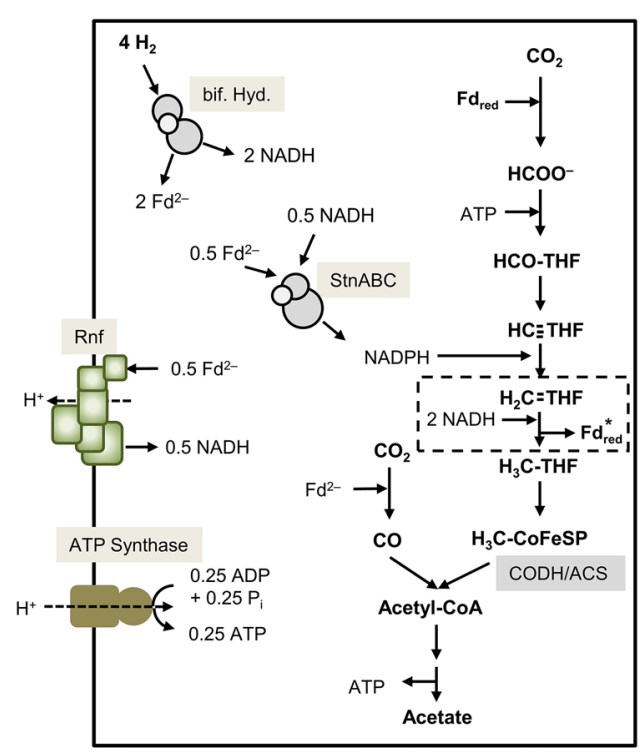

Figure 5. Biochemistry and bioenergetics of acetogenesis from $\mathrm{H}_{2}+\mathrm{CO}_{2}$ in S. ovata. For explanations, see text. ${ }^{\star}$ The MTHFR is proposed to be electron-bifurcating. The second electron acceptor is assumed to have similar redox properties to that of Fd. For simplicity reasons we suppose Fd as second electron acceptor in our model. Abbreviations: bif. Hyd., electron-bifurcating hydrogenase; Stn, Sporomusa type Nfn.

ferredoxin has to be figured out in further studies, which might also shed light on the mechanism of electronbifurcating hydrogenases.

The Stn complex exhibits NADH and $\mathrm{Fd}_{\text {red }}$-dependent NADP ${ }^{+}$reduction and the NADPH-dependent reduction of $\mathrm{NAD}^{+}$and $\mathrm{Fd}_{\mathrm{ox}}$ and, therefore, links the cellular $\mathrm{NADP}(\mathrm{H})$ pool with the $\mathrm{NAD}(\mathrm{H})$ and the Fd pool. We here describe, that the Stn complex catalyses the energetically downhill reaction of $\mathrm{NAD}^{+}$or $\mathrm{NADP}^{+}$reduction with $\mathrm{Fd}_{\mathrm{red}}$ and the reduction of $\mathrm{NAD}^{+}$with NADPH. Electron bifurcation implies the strict need of two electron acceptors, however, low rates of the thermodynamic favourable electron transfer are reported for several electronbifurcating enzymes. For example the electron-bifurcating hydrogenase of T. maritima shows $\mathrm{H}_{2}$ evolution when only $\mathrm{Fd}_{\text {red }}$ is available as electron donor ${ }^{47}$ and the Nfn complex of $C$. kluyveri catalyses electron transfer from $\mathrm{Fd}_{\text {red }}$ to NADP ${ }^{+19}$. We furthermore observed reduction of FMN or FAD with NADPH and a stimulating effect of both flavins in the bifurcation assay, indicating, that (depending on availability) one or the other flavin can be bound by the Stn complex, as already suggested for the electron-bifurcating hydrogenases of M. thermoacetica and D. fructosovorans ${ }^{16,21}$.

Inspection of genome sequences available revealed that Stn is widely distributed. Potential Stn-encoding gene clusters were found in Firmicutes, Proteobacteria and Synergistetes (Table 1). Furthermore, the before mentioned Nso complex ${ }^{22}$ is highly similar to the Stn complex and it seems reasonable that Nso might actually function as an $\mathrm{NADH}$-dependent $\mathrm{Fd}_{\text {red }}: \mathrm{NADP}^{+}$oxidoreductase in methanogenic archaea. The genome of S. ovata apparently only codes for the Stn complex but not the Nfn complex. Genome sequences of acetogens were screened and the presence of Stn and Nfn was found to be almost mutually exclusive (Table 2). Stn and Nfn distribution apparently does not follow a phylogenetic or a physiological trait. In 20 of 48 genomes of acetogens screened the stn gene cluster was found, whereas 27 of the genomes encode for one or more $n f n$ gene clusters (Table 2). A. woodii has one stn cluster. Although it does not use NADPH as reductant in the WLP, NADPH is likely used as reductant in anabolic redox reactions. Thermoacetogenium phaeum has two different Stn-encoding gene clusters, whereas $C$. carboxidivorans and C. magnum have genes coding for an Stn complex and for several copies of Nfn complexes. Three of the genomes encode different Nfn complexes. The presence of multiple copies of Nfn encoding genes is also observed in species other than the acetogens. The archaeon Pyrococcus furiosus has two copies of Nfn ${ }^{43,48}$ and NfnI and NfnII were not only demonstrated to be differentially expressed (expression of NfnI is upregulated during sugar fermentation, whereas expression of NfnII is upregulated during sulfur reduction) but the purified Nfn homologs had different catalytic properties. NfnI was shown to transfer electrons from NADPH to ferredoxin and $\mathrm{NAD}^{+}$simultaneously, whereas $\mathrm{NfnII}$ did not. NfnII exhibited $\mathrm{Fd}_{\text {red }}: \mathrm{NADP}^{+}$oxidoreductase activity without addition of NADH but electron transfer from NADPH to Fd was not catalysed, indicating that NfnII might need a second, so far unknown electron acceptor to facilitate this endergonic electron transfer ${ }^{48}$. These results suggest that different transhydrogenases are important for the organism to deal with different substrate availability and living mode (sugar fermentation and sulfur reduction) and that the integration of Nfn or Stn encoding gene clusters into the genome (e.g. by lateral gene transfer) might enhance the range of potential habitats and, hence, contributes in increasing the fitness of the organism. The search for Stn homologs did also show that there are organisms like C. drakei and T. primitia which neither have genes coding for an Stn nor an Nfn complex, which raises the question if there is a third, so far unknown protein complex with a similar function in these organisms. 
a

Nfn complex

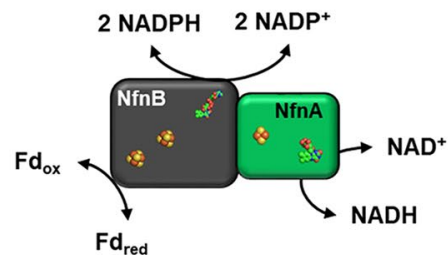

C Non-bifurcating hydrogenase (S. wolfei)

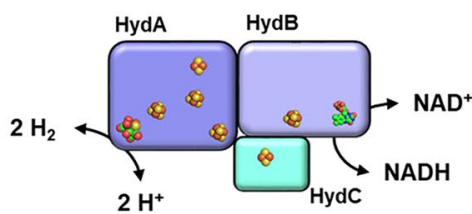

e

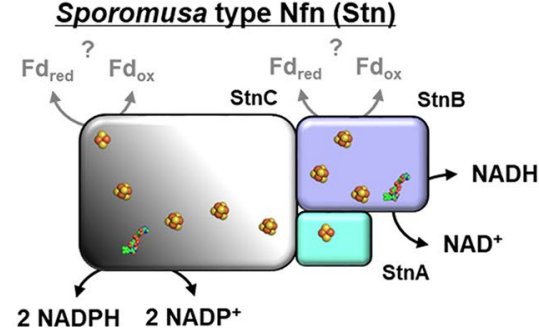

b

Electron-bifurcating hydrogenase (A. woodii)

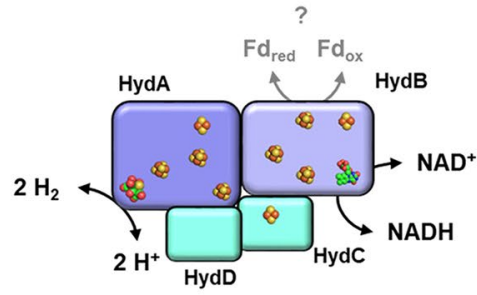

d
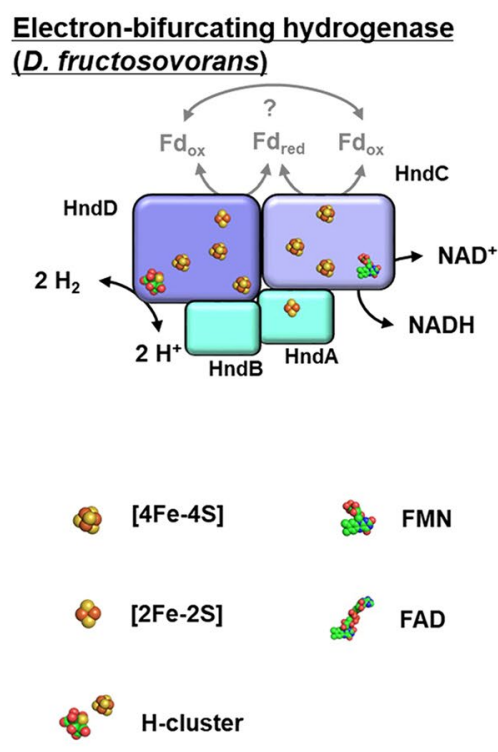

Figure 6. Model of Stn and homologous electron-bifurcating complexes. For explanations, see text. (a) The electron-bifurcating transhydrogenase Nfn is depicted. (b) The electron-bifurcating hydrogenase of $A$. woodii is depicted. (c) The non-bifurcating hydrogenase of $S$. wolfei is depicted. (d) The electron-bifurcating hydrogenase of $D$. fructosovorans is depicted. Fd is assumed to interact with HndC and HndD (e) The Sporomusa type Nfn is depicted. The FeS-strings were constructed arbitrarily.

\section{Methods}

Biochemicals and enzymes. $\mathrm{NAD}(\mathrm{P})^{+} \mathrm{NAD}(\mathrm{P}) \mathrm{H}, \mathrm{FAD}, \mathrm{FMN}$, methyl viologen, benzyl viologen, glucose-6-phosphate, glucose-6-phosphatate dehydrogenase, tetrahydrofolate and formaldehyde were obtained from Sigma-Aldrich Chemie GmbH (Taufkirchen, Germany). Materials used for protein purification via FPLC were obtained from GE Healthcare, Sweden. Ferredoxin (a $2 \times[4 \mathrm{Fe}-4 \mathrm{~S}]$-cluster ferredoxin) was purified from $C$. pasteurianum $^{49}$, CODH was purified from $A$. woodii $^{11}$.

Cultivation of S. ovata. S. ovata DSM 2662 was grown under strictly anoxic conditions at $30{ }^{\circ} \mathrm{C}$ on DSM medium 311 with $20 \mathrm{mM}$ fructose as carbon and energy source. Glycine betaine and $\mathrm{Na}_{2} \mathrm{~S} \times 9 \mathrm{H}_{2} \mathrm{O}$ were omitted and $0.6 \mathrm{~g} / \mathrm{l}$ Cystein- $\mathrm{HCl} \times \mathrm{H}_{2} \mathrm{O}$ was used as reducing agent, instead. Growth was monitored by measuring the optical density at $600 \mathrm{~nm}\left(\mathrm{OD}_{600}\right)$.

Preparation of cytoplasm and membrane fraction. All buffers contained 2 mM DTE as reducing agent and $4 \mu \mathrm{M}$ resazurin as redox indicator. Cells of $S$. ovata were harvested at late exponential growth phase $\left(\mathrm{OD}_{600}=2\right)$ and washed twice with buffer A $\left(50 \mathrm{mM}\right.$ Tris/ $\mathrm{HCl}, \mathrm{pH} 7.5 ; 20 \%$ Glycerin, $20 \mathrm{mM} \mathrm{MgSO}_{4}, 5 \mu \mathrm{M} \mathrm{FAD}$, $5 \mu \mathrm{M}$ FMN). Cells were resuspended in buffer A, $0.5 \mathrm{mM}$ PMSF and $0.1 \mathrm{mg} / \mathrm{ml}$ DNase I was added and the suspension was passed through a French pressure cell at $110 \mathrm{MPa}$. Cell debris was removed by centrifugation at $24,000 \times g$ for $45 \mathrm{~min}$. Cytoplasmic- and membrane fraction were separated by centrifugation at $210,000 \times g$ for $45 \mathrm{~min}$. For further use membrane fraction was washed twice in buffer A.

Purification of Sporomusa type Nfn (Stn). The cytoplasmic fraction was applied to a Q-Sepharose high performance column and eluted with a linear gradient from 0 to $400 \mathrm{mM} \mathrm{NaCl}$. The Stn eluted between $150 \mathrm{mM}$ $\mathrm{NaCl}$ and fractions with NADPH:MV oxidoreductase activity were pooled. $\left(\mathrm{NH}_{4}\right)_{2} \mathrm{SO}_{4}$ was added to a final con- 


\begin{tabular}{|c|c|c|c|c|}
\hline Organism & Locus tag of StnC & \% identitiy to StnC of S. ovata & Length [aa] & Phylum \\
\hline Acetoanaerobium sticklandii DSM 519 & CLOST_2294 & 45 & 1,195 & Firmicutes \\
\hline Acetomicrobium mobile DSM 13181 & Anamo_1498 & 45 & 1,071 & Synergistetes \\
\hline Alkaliphilus metalliredigens QYMF & Amet_3096 & 44 & 1,187 & Firmicutes \\
\hline Alkaliphilus oremlandii OhILAs & Clos_0277 & 46 & 1,192 & Firmicutes \\
\hline Ammonifex degensii $\mathrm{KC} 4$ & Adeg_0156 & 33 & 898 & Firmicutes \\
\hline Caldicellulosiruptor changbaiensis CBS-Z & Calcha_02442 & 51 & 1,178 & Firmicutes \\
\hline Caldicellulosiruptor naganoensis NA10 & N907DRAFT_1313 & 50 & 1,178 & Firmicutes \\
\hline Caldicellulosiruptor saccharolyticus DSM 8903 & Csac_0621 & 50 & 1,178 & Firmicutes \\
\hline Dehalobacter restrictus DSM 9455 & Dehre_2348 & 32 & 891 & Firmicutes \\
\hline Desulfitobacterium metallireducens DSM 15288 & Desme_0852 & 33 & 892 & Firmicutes \\
\hline Desulfosporosinus acidiphilus DSM 22704 & Desaci_0777 & 31 & 892 & Firmicutes \\
\hline Desulfosporosinus meridiei DSM 13257 & Desmer_0713 & 32 & 893 & Firmicutes \\
\hline Desulfosporosinus orientis DSM 765 & Desor_0661 & 32 & 893 & Firmicutes \\
\hline Desulfosporosinus sp. BG & Ga0165177_101659 & 51 & 1,204 & Firmicutes \\
\hline Desulfosporosinus sp. OT & DOT_1508 & 51 & 1,204 & Firmicutes \\
\hline Geoalkalibacter subterraneus Red1 & EJ58DRAFT_03287 & 45 & 1,192 & Proteobacteria \\
\hline Methylomusa anaerophila MMFC1 & Ga0398860_479 & 76 & 1,184 & Firmicutes \\
\hline Natranaerobius thermophilus JW/NM-WN-LF & Nther_1249 & 37 & 1,073 & Firmicutes \\
\hline Syntrophobotulus glycolicus DSM 8271 & Sgly_2685 & 31 & 894 & Firmicutes \\
\hline Syntrophomonas palmitatica JCM 14374 & Ga0128340_1167 & 46 & 1,071 & Firmicutes \\
\hline Terrisporobacter glycolicus DSM 1288 & G483DRAFT_1163 & 46 & 1,165 & Firmicutes \\
\hline Thermococcus litoralis DSM 5473 & OCC_03032 & 41 & 955 & Euryarchaeota \\
\hline Thermosediminibacter oceani DSM 16646 & Toce_0243 & 49 & 1,206 & Firmicutes \\
\hline Thermovirga lienii DSM 17291 & Tlie_1249 & 37 & 1,241 & Synergistetes \\
\hline
\end{tabular}

Table 1. Distribution of potential Stn-encoding gene clusters in bacteria and archaea.

centration of $2 \mathrm{M}$. The precipitate was removed by centrifugation $(24,000 \times \mathrm{g}, 30 \mathrm{~min})$ and the supernatant was applied to a Phenyl-Sepharose HP column, equilibrated with buffer $\mathrm{C}\left(=\right.$ buffer $\left.\mathrm{A}+2 \mathrm{M}\left(\mathrm{NH}_{4}\right)_{2} \mathrm{SO}_{4}\right)$. Elution was performed with a linear gradient from 2-0 $\mathrm{M}\left(\mathrm{NH}_{4}\right)_{2} \mathrm{SO}_{4}$ with buffer $\mathrm{D}$ (= buffer $\left.\mathrm{A}+250 \mathrm{mM} \mathrm{NaCl}\right)$. The activity eluted around $500 \mathrm{mM}\left(\mathrm{NH}_{4}\right)_{2} \mathrm{SO}_{4}$. Fractions with activity were pooled, concentrated using ultrafiltration in $100-\mathrm{kDa}$ Vivaspin tubes (Sartorius Stedim Biotech GmbH, Germany) and divided to avoid overloading of the following gel filtration on a Superdex 200 increase column (10/300 GL; GE-Healthcare). The gel filtration was equilibrated with buffer D and the Stn eluted at a volume of around $8.5 \mathrm{ml}$. Following, the sample was applied to a Blue-Sepharose HP column, which was equilibrated with buffer D. The Stn complex eluted by washing the column with $100 \%$ buffer B. The purified protein was stored in buffer $\mathrm{A}$ at $4{ }^{\circ} \mathrm{C}$.

Enzymatic activity assays. Except were indicated all enzyme activities were measured in anoxic glass cuvettes $(\mathrm{d}=0.2 \mathrm{~cm}$ or $0.5 \mathrm{~cm}$; Glasgerätebau Ochs, Germany) sealed by rubber stoppers in $100 \mathrm{mM}$ Tris/ $\mathrm{HCl}$ buffer ( $\mathrm{pH} 7.5$ ) under a $\mathrm{N}_{2}$-atmosphere. One unit is defined as transfer of $2 \mu \mathrm{mol}$ electrons $\times \mathrm{min}^{-1}$. All assays were performed in triplicates.

$N A D(P)^{+}$reduction with reduced ferredoxin (Rnf complex). To determine the Rnf activity in the membrane fraction $30 \mu \mathrm{M}$ ferredoxin were prereduced with $\mathrm{CODH}$ using a $\mathrm{CO}$-atmosphere. $1 \mathrm{mM} \mathrm{NAD}(\mathrm{P})^{+}$was added and the absorbance was followed at $340 \mathrm{~nm}\left(\varepsilon=6.3 \mathrm{mM}^{-1} \times \mathrm{cm}^{-1}\right)$ to determine the reduction of NAD(P) . The assay was performed in MOPS buffer $\left(50 \mathrm{mM}, \mathrm{pH}\right.$ 7) containing $10 \mathrm{mM} \mathrm{NaCl}$ and $20 \mathrm{mM} \mathrm{MgSO}_{4}$. Measurements were performed at $30^{\circ} \mathrm{C}$.

$N A D(P)^{+}$reduction with methylene-THF (methylene-THF dehydrogenase). The methylene-THF dehydrogenase activity of the cytoplasmic fraction was determined by following the reduction of $0.5 \mathrm{mM} \mathrm{NAD}(\mathrm{P})^{+}$with methylene-THF as electron donor. A racemic mixture of methylene-THF was produced non-enzymatically by adding $1.5 \mathrm{mM}$ formaldehyde and $0.5 \mathrm{mM}$ tetrahydrofolate to the buffer. Measurements were performed at $30^{\circ} \mathrm{C}$.

Reactions catalysed by the Stn complex. Methyl viologen or benzyl viologen with NAD $(P) H$. Reduction of $5 \mathrm{mM}$ MV with NADPH $(0.5 \mathrm{mM})$ or NADH $(0.5 \mathrm{mM})$ as electron donor was measured by following the absorbance at $604 \mathrm{~nm}\left(\varepsilon=13.9 \mathrm{mM}^{-1} \times \mathrm{cm}^{-1}\right)$. If BV $(5 \mathrm{mM})$ was used as electron acceptor the reduction of $\mathrm{BV}$ was measured by following the absorbance at $555 \mathrm{~nm}\left(\varepsilon=12 \mathrm{mM}^{-1} \times \mathrm{cm}^{-1}\right)$. Measurements were performed at $20^{\circ} \mathrm{C}$. 


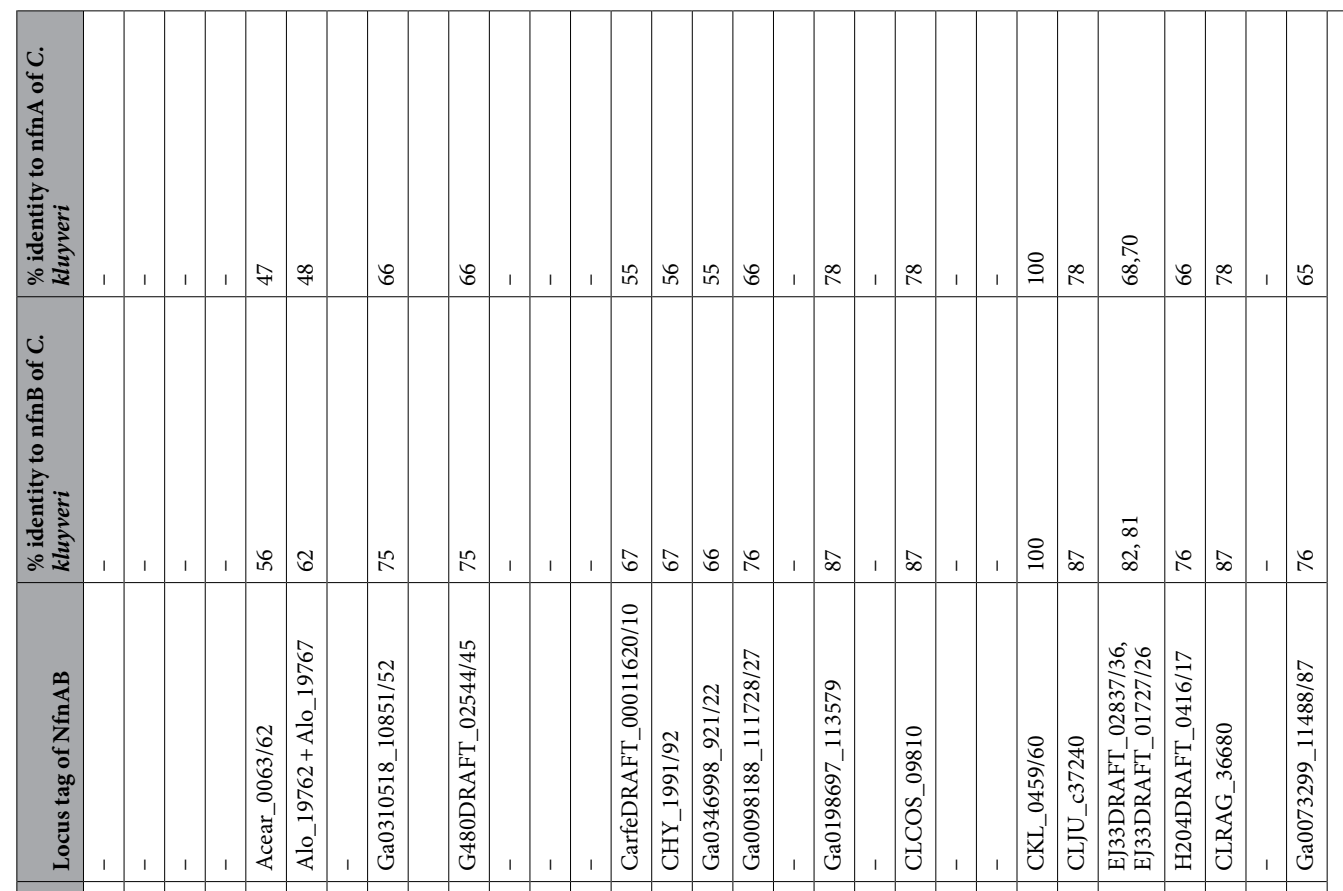

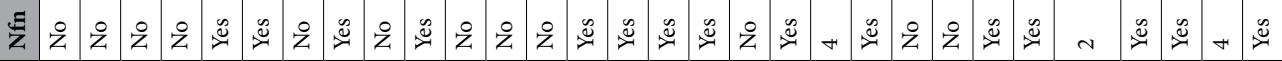

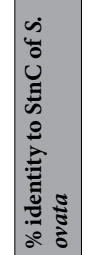

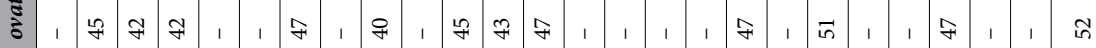

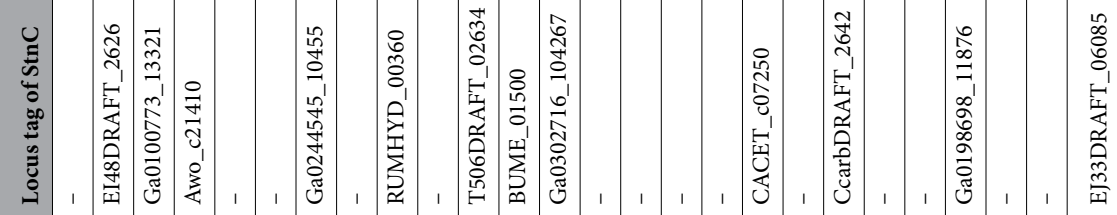

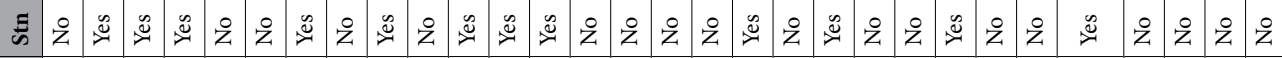

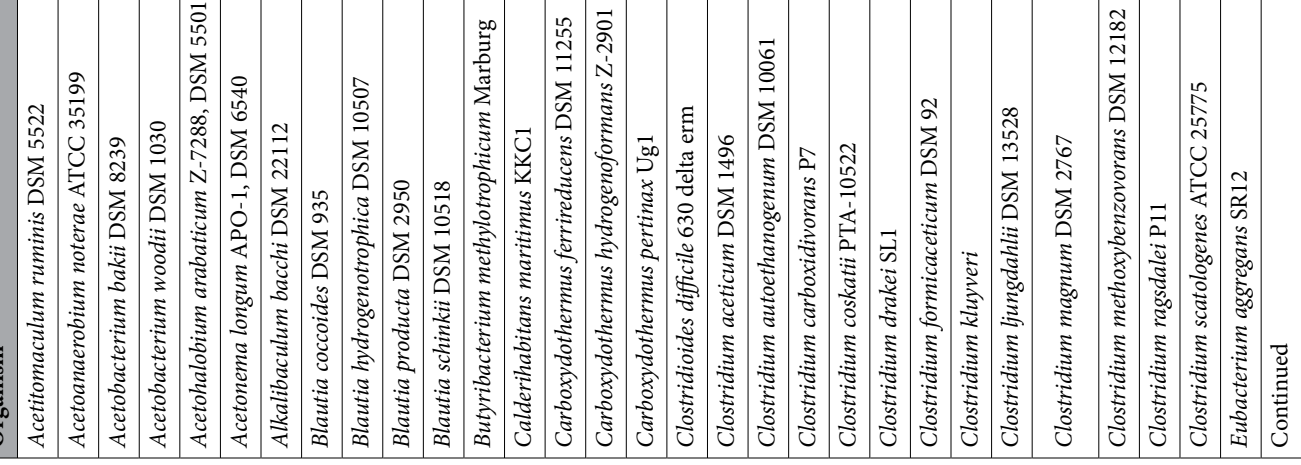




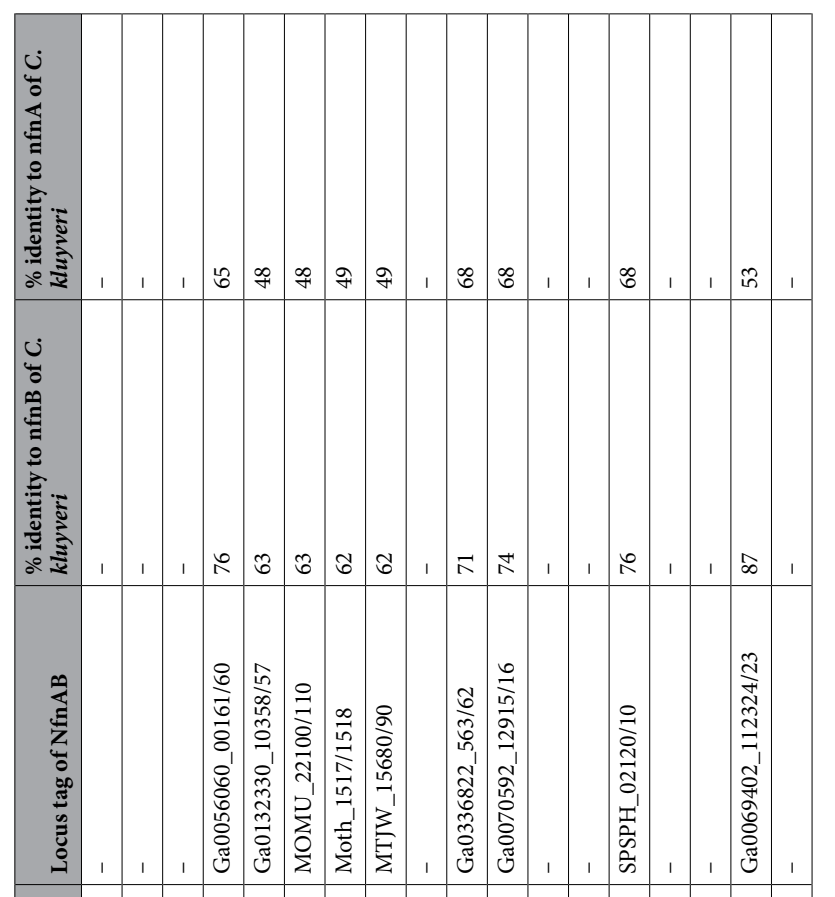

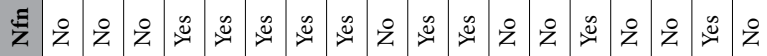

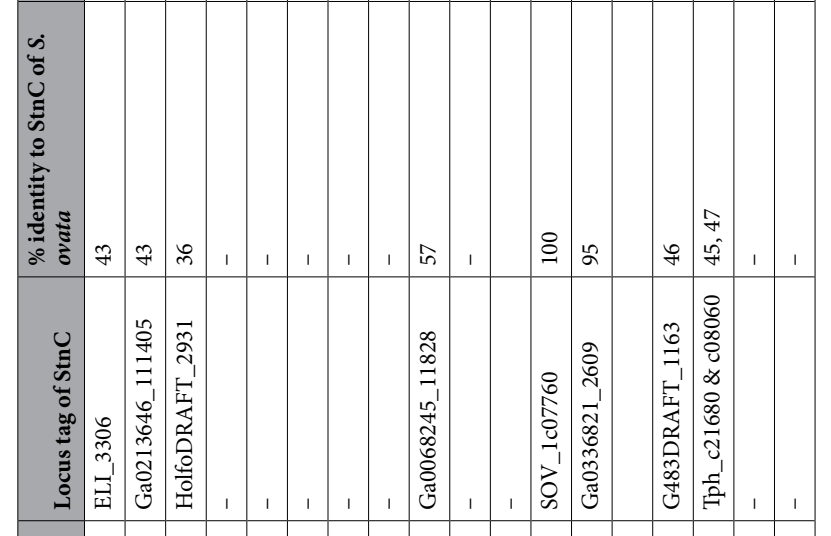

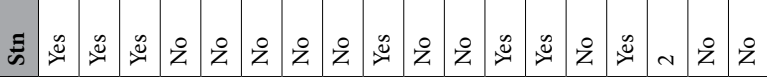

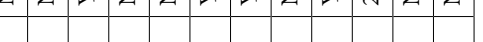

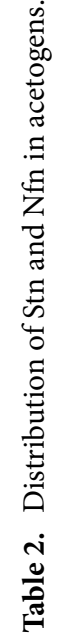


FAD, FMN or ferricyanide reduction with NADPH. To determine the reduction of FAD $(0.2 \mathrm{mM})$ or FMN $(0.2 \mathrm{mM})$ with NADPH $(0.25 \mathrm{mM})$ as electron donor, the absorbance of FAD $\left(\varepsilon=11.3 \mathrm{mM}^{-1} \times \mathrm{cm}^{-1}\right)$ or FMN was followed at $450 \mathrm{~nm}\left(\varepsilon=12.5 \mathrm{mM}^{-1} \times \mathrm{cm}^{-1}\right)$. Reduction of ferricyanide $(5 \mathrm{mM})$ with NADPH as electron donor was followed by measuring the absorbance at $420 \mathrm{~nm}\left(\varepsilon=1 \mathrm{mM}^{-1} \times \mathrm{cm}^{-1}\right)$. Measurements were performed at $20^{\circ} \mathrm{C}$.

Simultaneous reduction of ferredoxin and $\mathrm{NAD}^{+}$with $\mathrm{NADPH}$. Reduction of ferredoxin and $\mathrm{NAD}^{+}$with NADPH catalysed by the Stn complex was assayed at $50^{\circ} \mathrm{C}$ in $50 \mathrm{mM}$ Gly-Gly buffer (pH 8) containing $10 \mathrm{mM}$ $\mathrm{NaCl}$ and $20 \mathrm{mM} \mathrm{MgSO}_{4}$. To keep the level of NADPH constant, $0.25 \mathrm{mM} \mathrm{NADP}^{+}$were prereduced with 1 unit glucose-6-phosphate dehydrogenase and $20 \mathrm{mM}$ glucose-6-phosphate (NADP ${ }^{+}$reducing system) as reported earlier $^{19} .30 \mu \mathrm{M}$ ferredoxin and $0.5 \mathrm{mM} \mathrm{NAD}^{+}$were used as electron acceptors. To determine the reduction of ferredoxin and the reduction of $\mathrm{NAD}^{+}$the absorbance was followed at $430 \mathrm{~nm}\left(\varepsilon_{\Delta \text { ox-red }}=13.1 \mathrm{mM}^{-1} \times \mathrm{cm}^{-1}\right)$ and at $340 \mathrm{~nm}\left(\varepsilon=6.3 \mathrm{mM}^{-1} \times \mathrm{cm}^{-1}\right)$, respectively. To determine the reduction $\mathrm{NAD}^{+}$with NADPH, ferredoxin was omitted.

$\mathrm{NADP}^{+}$reduction with $\mathrm{NADH}$ and reduced ferredoxin. $\mathrm{NADP}^{+}$reduction catalysed by the Stn complex was assayed at $50^{\circ} \mathrm{C}$ in $50 \mathrm{mM}$ Gly-Gly buffer $\left(\mathrm{pH}\right.$ 8) containing $10 \mathrm{mM} \mathrm{NaCl}$ and $20 \mathrm{mM} \mathrm{MgSO}_{4} .30 \mu \mathrm{M}$ ferredoxin were prereduced with $\mathrm{CODH}$ using a CO-atmosphere. $0.25 \mathrm{mM} \mathrm{NADH}$ and $0.5 \mathrm{mM} \mathrm{NADP}^{+}$was added and the change of absorbance at $340 \mathrm{~nm}$ was followed to determine $\mathrm{NAD}^{+}$reduction. To determine $\mathrm{NAD}(\mathrm{P})^{+}$reduction with reduced ferredoxin, $\mathrm{NADH}$ was omitted.

Analytical methods. The protein concentration was determined according to Bradford ${ }^{50}$. Proteins were separated in $12 \%$ polyacrylamide gels and stained with coomassie brilliant blue G250. The iron content was determined calorimetrically according to $\mathrm{Fish}^{34}$. The nature of the flavin was determined as described before ${ }^{51}$.

Heterologous expression StnA, StnB and StnC. The single subunits of the Stn complex were amplified using Phusion DNA polymerase (New England BioLabs; Ipswitch, MA) and genomic DNA of S. ovata as template. Primers used were: $5^{\prime}$-tttcatatgtggagccacccgcagttcgaaaaatctgcgtgtaattcgtgcgaaaaagagct- $3^{\prime}$ and $5^{\prime}$-tttggatccctaaccttcacttacaacaccgcctttc- $3^{\prime}$ for $\sin A, 5^{\prime}$-tttcatatgtggagccacccgcagttcgaaaaatctgcggtgaaggttagagtaggtcttgg- $3^{\prime}$ and $5^{\prime}$-tttggatccctactcgatacaaactgcgtctaat- $3^{\prime}$ for $\sin B$ and $5^{\prime}$-tttcatatgtggagccaccegcagttcgaaaaatctgcgagcaaaattagtataaatataaatggccgc- $3^{\prime}$ and $5^{\prime}$-tttggatccctacaaactctgcctaccatttacaaaattc- $3^{\prime}$ for $\operatorname{stn} C$. The PCR products were cloned into the NdeI and BamHI restriction sites of pET21a and subsequently, the constructs were used to transform $E$. coli $\mathrm{HB} 101$. Plasmids were verified by DNA sequencing and introduced to E. coli BL21 (DE3) $\Delta i s c R$, which was already used for the successful production of iron sulfur-cluster containing proteins. Production and purification of the Stn subunits was performed as described earlier ${ }^{35}$.

Received: 28 May 2020; Accepted: 7 August 2020

Published online: 10 September 2020

\section{References}

1. Martin, W. \& Russell, M. J. On the origin of biochemistry at an alkaline hydrothermal vent. Philos. Trans. R. Soc. Lond. B Biol. Sci. 362, 1887-1925 (2007).

2. Martin, W. F. Hydrogen, metals, bifurcating electrons, and proton gradients: the early evolution of biological energy conservation. FEBS Lett. 586, 485-493 (2012).

3. Ragsdale, S. W. \& Pierce, E. Acetogenesis and the Wood-Ljungdahl pathway of $\mathrm{CO}_{2}$ fixation. Biochim. Biophys. Acta 1784, 18731898 (2008).

4. Drake, H. L., Gößner, A. S. \& Daniel, S. L. Old acetogens, new light. Ann. N. Y. Acad. Sci. 1125, 100-128 (2008).

5. Schuchmann, K. \& Müller, V. Autotrophy at the thermodynamic limit of life: a model for energy conservation in acetogenic bacteria. Nat. Rev. Microbiol. 12, 809-821 (2014).

6. Schuchmann, K. \& Müller, V. Energetics and application of heterotrophy in acetogenic bacteria. Appl. Environ. Microbiol. 82, 4056-4069 (2016)

7. Biegel, E. \& Müller, V. Bacterial $\mathrm{Na}^{+}$-translocating ferredoxin:NAD ${ }^{+}$oxidoreductase. Proc. Natl. Acad. Sci. U.S.A. 107, 18138-18142 (2010).

8. Biegel, E., Schmidt, S., González, J. M. \& Müller, V. Biochemistry, evolution and physiological function of the Rnf complex, a novel ion-motive electron transport complex in prokaryotes. Cell. Mol. Life Sci. 68, 613-634 (2011).

9. Westphal, L., Wiechmann, A., Baker, J., Minton, N. P. \& Müller, V. The Rnf complex is an energy coupled transhydrogenase essential to reversibly link cellular NADH and ferredoxin pools in the acetogen Acetobacterium woodii. J. Bacteriol. 200, e00357-e1318 (2018).

10. Schölmerich, M. C. \& Müller, V. Energy conservation by a hydrogenase-dependent chemiosmotic mechanism in an ancient metabolic pathway. Proc. Natl. Acad. Sci. U.S.A. 116, 6329-6334 (2019).

11. Hess, V., Schuchmann, K. \& Müller, V. The ferredoxin:NAD ${ }^{+}$oxidoreductase (Rnf) from the acetogen Acetobacterium woodii requires $\mathrm{Na}^{+}$and is reversibly coupled to the membrane potential. J. Biol. Chem. 288, 31496-31502 (2013).

12. Tremblay, P. L., Zhang, T., Dar, S. A., Leang, C. \& Lovley, D. R. The Rnf complex of Clostridium ljungdahlii is a proton-translocating ferredoxin:NAD ${ }^{+}$oxidoreductase essential for autotrophic growth. MBio 4, e00406-00412 (2012).

13. Hess, V., Poehlein, A., Weghoff, M. C., Daniel, R. \& Müller, V. A genome-guided analysis of energy conservation in the thermophilic, cytochrome-free acetogenic bacterium Thermoanaerobacter kivui. BMC Genom. 15, 1139 (2014).

14. Schuchmann, K., Chowdhury, N. P. \& Müller, V. Complex multimeric [FeFe] hydrogenases: biochemistry, physiology and new opportunities for the hydrogen economy. Front. Microbiol. 9, 2911 (2018).

15. Wang, S. et al. NADP-specific electron-bifurcating [FeFe]-hydrogenase in a functional complex with formate dehydrogenase in Clostridium autoethanogenum grown on CO. J. Bacteriol. 195, 4373-4386 (2013). 
16. Wang, S., Huang, H., Kahnt, J. \& Thauer, R. K. A reversible electron-bifurcating ferredoxin- and NAD-dependent [FeFe]-hydrogenase (HydABC) in Moorella thermoacetica. J. Bacteriol. 195, 1267-1275 (2013).

17. $\mathrm{Li}$, F. et al. Coupled ferredoxin and crotonyl coenzyme A $(\mathrm{CoA})$ reduction with NADH catalyzed by the butyryl-CoA dehydrogenase/Etf complex from Clostridium kluyveri. J. Bacteriol. 190, 843-850 (2008).

18. Schuchmann, K. \& Müller, V. A bacterial electron bifurcating hydrogenase. J. Biol. Chem. 287, 31165-31171 (2012).

19. Wang, S., Huang, H., Moll, J. \& Thauer, R. K. NADP ${ }^{+}$reduction with reduced ferredoxin and $\mathrm{NADP}^{+}$reduction with NADH are coupled via an electron bifurcating enzyme complex in Clostridium kluyveri. J. Bacteriol. 192, 5115-5123 (2010).

20. Poehlein, A., Gottschalk, G. \& Daniel, R. First insights into the genome of the Gram-negative, endospore-forming organism Sporomusa ovata strain H1 DSM 2662. Genome Announc. 1, e00734-13. https://doi.org/10.1128/genomeA.00734-13 (2013).

21. Kpebe, A. et al. A new mechanistic model for an $\mathrm{O}_{2}$-protected electron-bifurcating hydrogenase, Hnd from Desulfovibrio fructosovorans. Biochim. Biophys. Acta Bioenerg. 1859, 1302-1312 (2018).

22. Toth, A., Takacs, M., Groma, G., Rakhely, G. \& Kovacs, K. L. A novel NADPH-dependent oxidoreductase with a unique domain structure in the hyperthermophilic archaeon, Thermococcus litoralis. FEMS Microbiol. Lett. 282, 8-14 (2008).

23. Losey, N. A., Mus, F., Peters, J. W., Le, H. M. \& McInerney, M. J. Syntrophomonas wolfei uses an NADH-dependent, ferredoxinindependent [FeFe]-hydrogenase to reoxidize NADH. Appl. Environ. Microbiol. 83, e01335-17. https://doi.org/10.1128/AEM.01335 -17 (2017).

24. Leif, H., Sled, V. D., Ohnishi, T., Weiss, H. \& Friedrich, T. Isolation and characterization of the proton-translocating NADH: ubiquinone oxidoreductase from Escherichia coli. Eur. J. Biochem. 230, 538-548 (1995).

25. Malki, S. et al. Characterization of an operon encoding an NADP-reducing hydrogenase in Desulfovibrio fructosovorans. J. Bacteriol. 177, 2628-2636 (1995).

26. Wierenga, R. K., Terpstra, P. \& Hol, W. G. Prediction of the occurrence of the ADP-binding $\beta \alpha \beta$-fold in proteins, using an amino acid sequence fingerprint. J. Mol. Biol. 187, 101-107 (1986).

27. McKie, J. H. \& Douglas, K. T. Evidence for gene duplication forming similar binding folds for NAD $(\mathrm{P}) \mathrm{H}$ and FAD in pyridine nucleotide-dependent flavoenzymes. FEBS Lett. 279, 5-8 (1991).

28. Walker, J. E. The NADH-ubiquinone oxidoreductase (Complex-I) of respiratory chains. Q. Rev. Biophys. 25, 253-324 (1992).

29. Ma, K. \& Adams, M. W. W. Sulfide dehydrogenase from the hyperthermophilic archaeon Pyrococcus furiosus: a new multifunctional enzyme involved in the reduction of elemental sulfur. J. Bacteriol. 176, 6509-6517 (1994).

30. Ma, K. \& Adams, M. W. W. Ferredoxin:NADP oxidoreductase from Pyrococcus furiosus. Methods Enzymol. 334, 40-45 (2001).

31. Lubner, C. E. et al. Mechanistic insights into energy conservation by flavin-based electron bifurcation. Nat. Chem. Biol. 13, 655-659 (2017).

32. Kaufmann, F. \& Lovley, D. R. Isolation and characterization of a soluble NADPH-dependent Fe(III) reductase from Geobacter sulfurreducens. J. Bacteriol. 183, 4468-4476 (2001).

33. Scrutton, N. S., Berry, A. \& Perham, R. N. Redesign of the coenzyme specificity of a dehydrogenase by protein engineering. Nature 343, 38-43 (1990).

34. Fish, W. W. Rapid colorimetric micromethod for the quantitation of complexed iron in biological samples. Methods Enzymol. 158, 357-364 (1988).

35. Demmer, J. K. et al. Molecular basis of the flavin-based electron-bifurcating caffeyl-CoA reductase reaction. FEBS Lett. 592, 332-342 (2018).

36. Liu, C. L. \& Mortenson, L. E. Formate dehydrogenase of Clostridium pasteurianum. J. Bacteriol. 159, 375-380 (1984).

37. Mock, J., Wang, S., Huang, H., Kahnt, J. \& Thauer, R. K. Evidence for a hexaheteromeric methylenetetrahydrofolate reductase in Moorella thermoacetica. J. Bacteriol. 196, 3303-3314 (2014).

38. Müller, V., Chowdhury, N. P. \& Basen, M. Electron bifurcation: a long-hidden energy-coupling mechanism. Annu. Rev. Microbiol. 72, 331-353 (2018).

39. Buckel, W. \& Thauer, R. K. Flavin-based electron bifurcation, ferredoxin, flavodoxin, and anaerobic respiration with protons (Ech) or $\mathrm{NAD}^{+}$(Rnf) as electron acceptors: a historical review. Front. Microbiol. 9, 401 (2018).

40. Peters, J. W., Miller, A. F., Jones, A. K., King, P. W. \& Adams, M. W. Electron bifurcation. Curr. Opin. Chem. Biol. 31, 146-152 (2016).

41. Buckel, W. \& Thauer, R. K. Flavin-based electron bifurcation, a new mechanism of biological energy coupling. Chem. Rev. 118, 3862-3886 (2018).

42. Nitschke, W. \& Russel, M. J. Redox bifurcations: mechanisms and importance to life now, and at its origin. BioEssays 34, 106-109 (2012).

43. Liang, J., Huang, H. \& Wang, S. Distribution, evolution, catalytic mechanism, and physiological functions of the flavin-based electron-bifurcating NADH-dependent reduced ferredoxin: $\mathrm{NADP}^{+}$oxidoreductase. Front. Microbiol. 10, 373 (2019).

44. Demmer, J. K. et al. Insights into flavin-based electron bifurcation $v i a$ the NADH-dependent reduced ferredoxin:NADP ${ }^{+}$oxidore- $^{-}$ ductase structure. J. Biol. Chem. 290, 21985-21995 (2015).

45. Buckel, W. \& Thauer, R. K. Energy conservation via electron bifurcating ferredoxin reduction and proton/ $/ \mathrm{Na}^{+}$translocating ferredoxin oxidation. Biochim. Biophys. Acta 1827, 94-113 (2013).

46. Peters, J. W., Beratan, D. N., Schut, G. J. \& Adams, M. W. W. On the nature of organic and inorganic centers that bifurcate electrons, coupling exergonic and endergonic oxidation-reduction reactions. Chem. Commun. 54, 4091-4099 (2018).

47. Schut, G. J. \& Adams, M. W. W. The iron-hydrogenase of Thermotoga maritima utilizes ferredoxin and NADH synergistically: a new perspective on anaerobic hydrogen production. J. Bacteriol. 191, 4451-4457 (2009).

48. Nguyen, D. M. N. et al. Two functionally distinct $\mathrm{NADP}^{+}$-dependent ferredoxin oxidoreductases maintain the primary redox balance of Pyrococcus furiosus. J. Biol. Chem. 292, 14603-14616 (2017).

49. Schönheit, P., Wäscher, C. \& Thauer, R. K. A rapid procedure for the purification of ferredoxin from Clostridia using polyethylenimine. FEBS Lett. 89, 219-222 (1978).

50. Bradford, M. M. A rapid and sensitive method for the quantification of microgram quantities of protein utilizing the principle of proteine-dye-binding. Anal. Biochem. 72, 248-254 (1976).

51. Bertsch, J., Parthasarathy, A., Buckel, W. \& Müller, V. An electron-bifurcating caffeyl-CoA reductase. J. Biol. Chem. 288, 1130411311 (2013).

\section{Acknowledgements}

This project has received funding from the European Research Council (ERC) under the European Union's Horizon 2020 research and innovation programme (Grant Agreement No. 741791) and the German Research Foundation (DFG).

\section{Author contributions}

F.K. and V.M. designed research. F.K. and J.R. performed research. F.K. and V.M. analyzed data and wrote the manuscript. 


\section{Funding}

Open access funding provided by Projekt DEAL.

\section{Competing interests}

The authors declare no competing interests.

\section{Additional information}

Supplementary information is available for this paper at https://doi.org/10.1038/s41598-020-71038-2.

Correspondence and requests for materials should be addressed to V.M.

Reprints and permissions information is available at www.nature.com/reprints.

Publisher's note Springer Nature remains neutral with regard to jurisdictional claims in published maps and institutional affiliations.

Open Access This article is licensed under a Creative Commons Attribution 4.0 International License, which permits use, sharing, adaptation, distribution and reproduction in any medium or
format, as long as you give appropriate credit to the original author(s) and the source, provide a link to the Creative Commons licence, and indicate if changes were made. The images or other third party material in this article are included in the article's Creative Commons licence, unless indicated otherwise in a credit line to the material. If material is not included in the article's Creative Commons licence and your intended use is not permitted by statutory regulation or exceeds the permitted use, you will need to obtain permission directly from the copyright holder. To view a copy of this licence, visit http://creativecommons.org/licenses/by/4.0/.

(c) The Author(s) 2020 